\title{
Light Trapping at the Time of the Atmospheric Radio Disturbances (SEA)
}

\section{Nowinszky L*, Puskas J and Kiss M}

Eotvos Lorand University, Savaria Campus Savaria Science Centre, Hungary

*Corresponding author: Laszlo Nowinszky, Eötvös Loránd University, Savaria Campus Savaria Science Centre, 9700 Szombathely Károlyi Gáspár Square 4. Hungary, Email: lnowinszky@ gmail.com

\section{Research Article}

Volume 4 Issue 4

Received Date: May 25, 2020

Published Date: June 08, 2020

DOI: $10.23880 /$ jenr-16000202

\section{Abstract}

The study deals with the connection with the atmospheric radio disturbances (SEA) and the light-trap catch of five moth species. The atmospheric radio disturbances become intensive 8 minutes after sun flares (appearance of sun protuberances). At the time of atmospheric radio disturbances, the catches of the European Corn-borer (Ostrinia nubilalis Hbn., the Microlepidoptera spec. indet. and the Setaceous Hebrew Character (Xestia c-nigrum L.) increased parallel of the values of atmospheric radio disturbances (SEA). In contrast the catches of Fall Webworm (Hyphantria cunea Drury) and the Turnip moth (Agrotis segetum Den. \& Schiff.) decreased.

Keywords: Atmospheric Radio Disturbances (SEA); Light-Trap; Moths

\section{Introduction}

Solar eruptions are accompanied by intensive X-ray, gamma and corpuscular radiation that, when they reach the Earth and interact with its upper atmosphere and change the electromagnetic conditions that currently exist [1]. This can lead to magnetic storms and changes in the ionization conditions of the ionosphere.

At least 8 minutes after the appearance of a solar flare, atmospheric radio noise (Sudden Enhancement of Atmospherics $=$ SEA) measured at $27 \mathrm{kHz}(11 \mathrm{~km}$ wavelength $)$ is suddenly amplified. The SEA occurs after every major flare proportionately.

Flares of importance one (they are relatively frequent) are followed by SEA in about $10 \%$ of all cases, this proportion is $50 \%$ in the case of flares of importance two, while the proportion is $90 \%$ in the case of the strongest flares, those of importance three. SEA can be observed by very simple radiotechnological equipment, even in cloudy weather, provides information easy to handle and is also suitable for an indirect detection of flares [2].

We do not know any publications in the Hungarian and international literature that examines the effectiveness of light-trap catch of insects in relationship with ionospheric disturbances or atmospheric radio noise. However, Becker [3] and Damaschke and Becker [4] established a negative correlation between atmospheric radio noises and the oxygen intake of termites. Later on, Becker and Gerisch [5] were able to prove their effect also on the feeding activity of termites.

In a previous study [6], we have already published partial results on this topic for Turnip Moth (Agrotis segetum Den. \& Schiff.

\section{Material and Methods}

Atmospheric radio disturbances data (SEA) measured at $27 \mathrm{kHz}$ was used from the publications of the Panská Ves Observatory of the Geophysical Research Institute of the Czech Academy of Sciences. This observation station 
is about 25-30 kilometres from Prague. According to Béla Szudár (Main Meteorological Station, Békéscsaba), the comparison of the values measured there with the light-trap collection data in Hungary is scientifically justified (Personal communication).

The National Light-trap Network was in operation, equipped uniformly with Jermy type light-traps, and it has been operating in Hungary since 1958. There were selected the collection data of the five moth (Lepidoptera) species for studied from the 43 light-trap stations in years $1967,1968,1969$. Atmospheric radio interference was also available to us from the years we studied $(1967,1968,1969)$. All light traps did not work in all three years. The catching data are shown in Table 1.

\begin{tabular}{|c|c|c|c|}
\hline \multirow{2}{*}{ Species } & \multicolumn{3}{|c|}{ Number of } \\
\hline & Moths & Data & Nights \\
\hline \multicolumn{4}{|l|}{ Crambidae, Pyraustinae } \\
\hline European Corn-borer (Ostrinia nubilalis Hübner, 1796) & 8,258 & 1,550 & 135 \\
\hline Microlepidoptera spec. indet. & 76,555 & 2,830 & 135 \\
\hline \multicolumn{4}{|l|}{ Erebidae, Arctiinae } \\
\hline Fall Webworm (Hyphantria cunea Drury, 1773) & 5,017 & 1,578 & 119 \\
\hline \multicolumn{4}{|l|}{ Noctuidae, Noctuinae } \\
\hline Turnip Moth (Agrotis segetum Denis \& Schiffermüller, 1775) & 12,272 & 1,398 & 135 \\
\hline Setaceous Hebrew Character (Xestia c-nigrum Linnaeus, 1758) & 26,120 & 6,869 & 135 \\
\hline
\end{tabular}

Table 1: Catching data of investigated species.

Note for the Table 1: The unidentified moth specimens were recorded as "Microlepidoptera spec. indet." They could not be identified because they were injured.

The number of individuals of a given species in variant years and villages or towns is not the same. Therefore, we computed relative catch (RC) values. This is for a given sampling time unit (one night) and the average number individuals per unit time of sampling, the number of swarming divided by the influence of individuals. Using relative catch values might solve this problem [7].

Relative catch values were calculated from the number of individuals of each investigated species for sampling nights per all 3 years to compare the differing sampling data. The RC was defined as the quotient of the number of caught individuals during a sampling time unit (1 night) per the average catch of individuals within the same swarming relating to the same time unit. For example, when the actual catch is equal to the average individual number captured in the same swarming, the RC is 1 .

The values of atmospheric radio disturbances were put into groups. The number of groups was determined according to Sturges method [8]. The corresponding relative catch data of the investigated species were arranged into these groups and afterwards the values were summarized and averaged. Relative catch values were placed according to the given day, then were summed up, averaged and depicted. Figures 1-5 also show the confidence intervals.

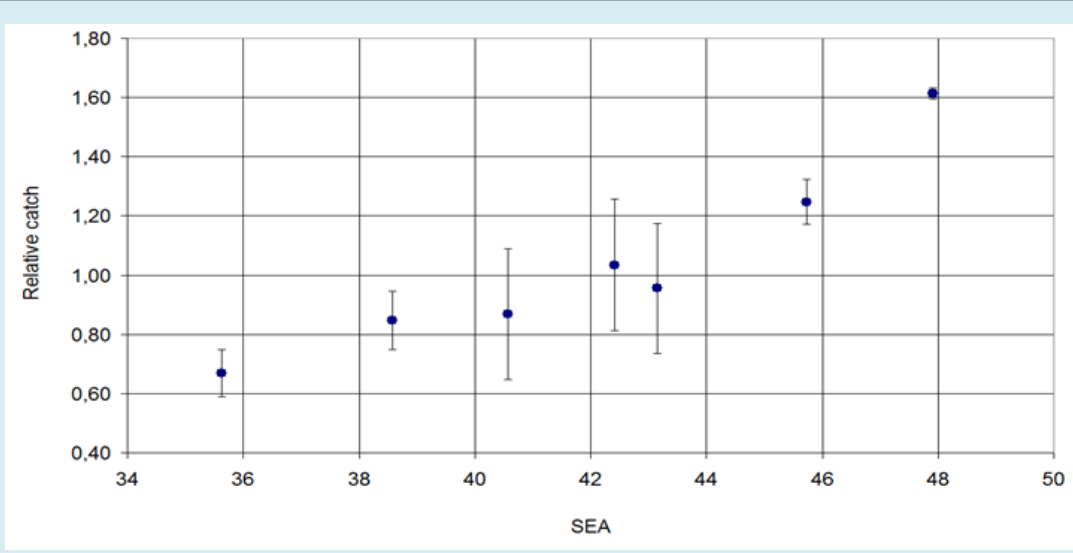

Figure 1: Light-trap catch of European Corn-borer (Ostrinal nubailalis Hubner) in connection with the atmospheric disturbances (SEA). 


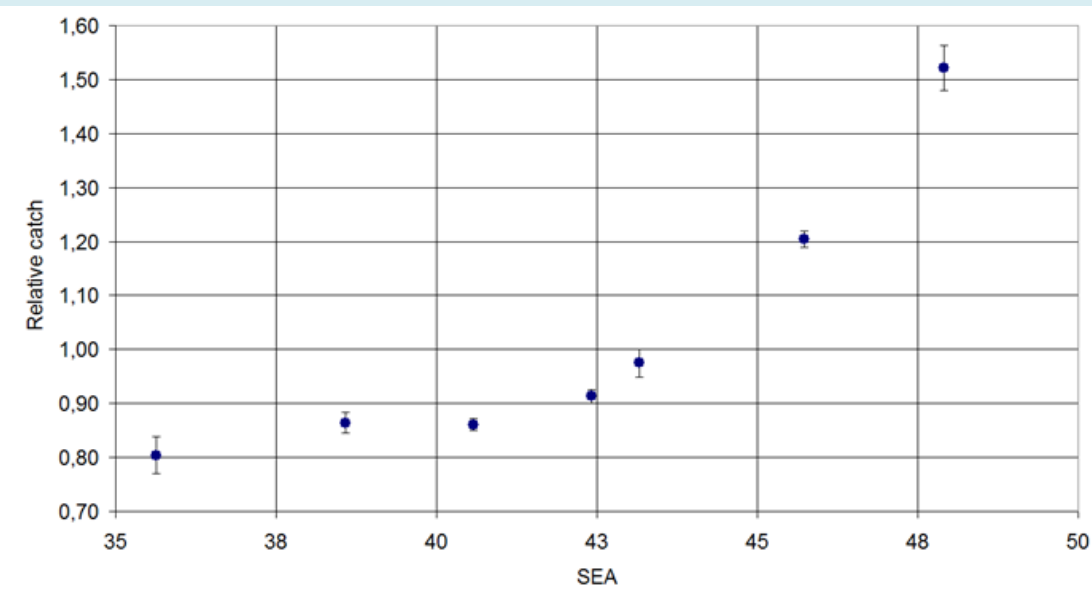

Figure 2: Light-trap catch of Microlepidoptera spec. indet. in connection with the atmospheric disturbances (SEA).

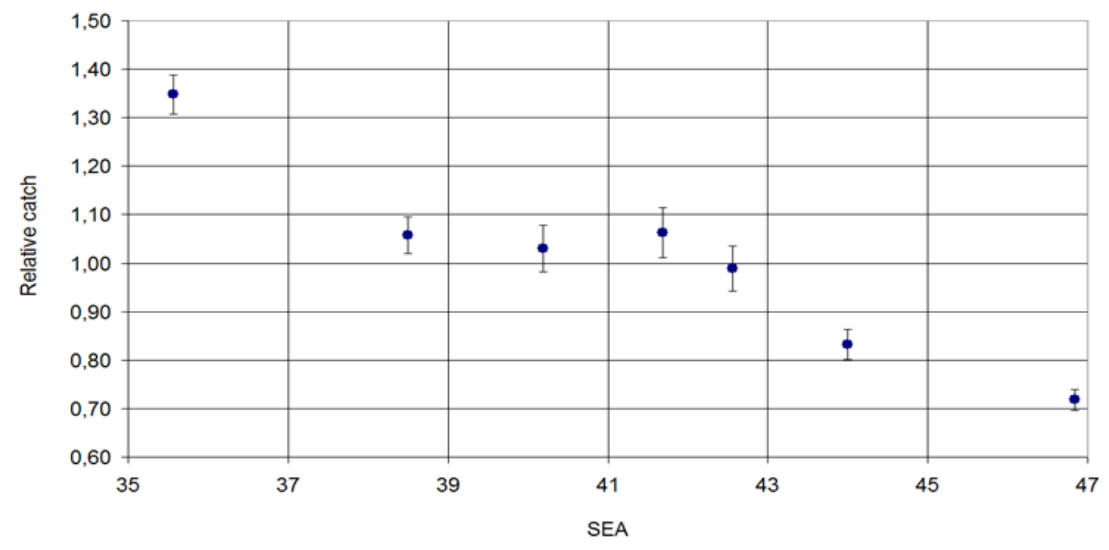

Figure 3: Light-trap catch of Fall Webworm Moth (Hyphantria cunae Drury) in connection with the atmospheric disturbances (SEA).

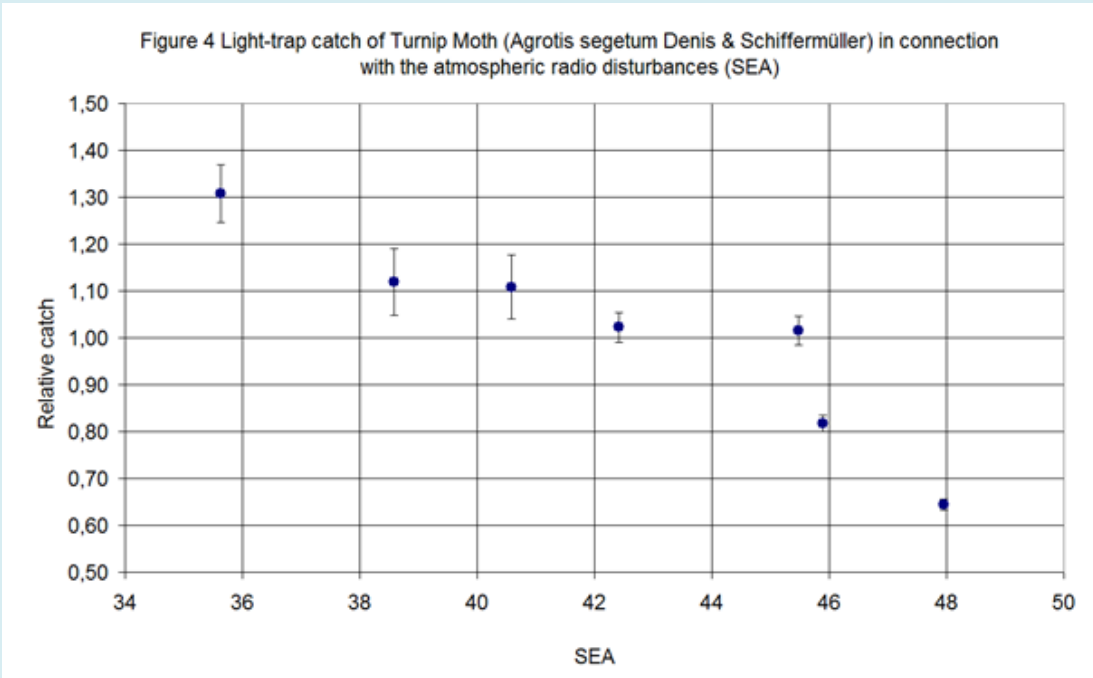

Figure 4: Light-trap catch of Fall Turnip Moth (Agrotis segetum Denis \& Schiffermuller) in connection with the atmospheric disturbances (SEA). 


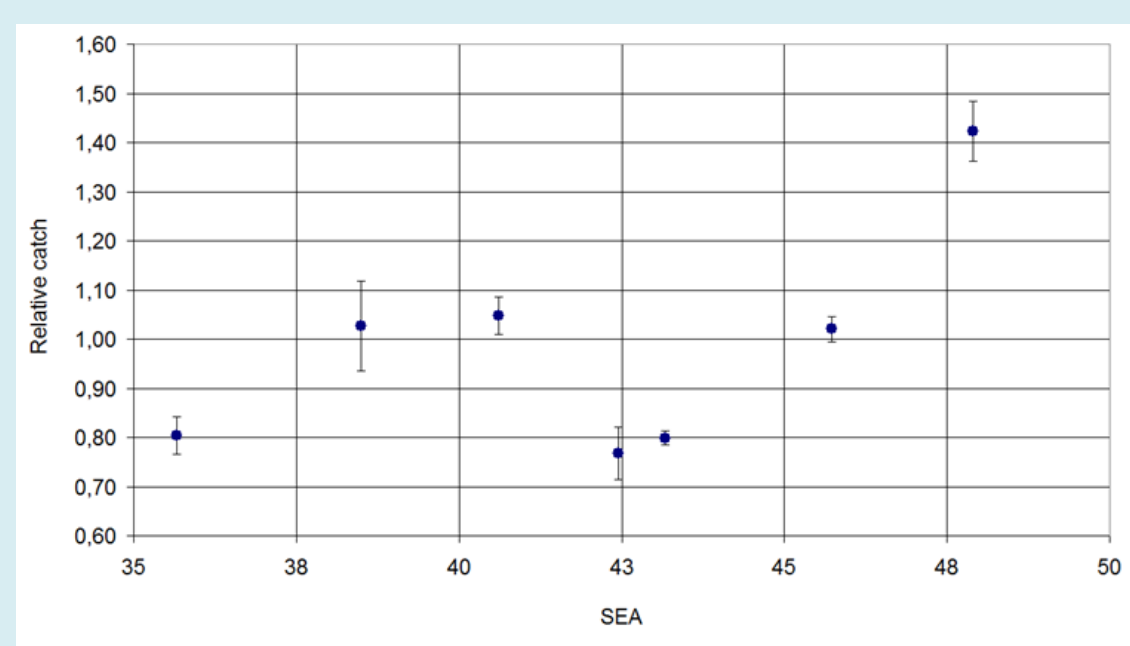

Figure 5: Light-trap catch of Setaceous Hebrew Character (Xestia c-nigrum Linnaeous, 1758) in connection with the atmospheric disturbances (SEA).

\section{Results and Discussion}

According to our results, the catch of European Cornborer (Ostrinia nubilalis Hbn.), Microlepidoptera sp. indet and Setaceous Hebrew Character (Xestia c-nigrum L.) increases in parallel with increasing values of SEA. In contrast, the catch of Fall Webworm (Hyphantria cunea Drury) and Turnip Moth (Agrotis segetum Den. \& Schiff.) decreases to the increasing values of SEA.

We have already shown in our previous studies that individuals of each species respond differently to the same environmental effects. Our current results show this as well. However, it is possible that the effects are favourable for all species, only the reaction to them is different. Our assumption is as follows:

Low relative catch values always refer to environmental factors in which the flight activity of insects diminishes. However, high values are not so clear to interpret. Major environmental changes bring about physiological transformation in the insect organism. The imago is shortlived; therefor unfavourable environmental endangers the survival of not just the individual but the species as a whole. In our hypothesis, the individual may adopt two kinds of strategies to evade the impacts hindering the normal functioning of its life phenomena. It may either display more liveliness, by increasing the intensity of its flight, copulation and egg-laying activity or take refuge in passivity to environmental factors of an unfavourable situation. By the present state of our knowledge we might say that unfavourable environmental factors might be accompanied by both high and low catch [7].

\section{Conclusions}

According to our results the atmospheric radio interferences influence the effectiveness of light-trapping insect collection. However, different species do not behave in the same way at low and high values of SEA.

Our recent work calls attention of entomologists to new and perhaps even more influential environmental factors, the atmospheric radio disturbances.

\section{References}

1. Smith HJ, Smith EvP (1963) Solar flares. Macmillan Co., New York, pp: 426.

2. Del Vecchio PI (1959) Indirect detection of solar flares. Sky and Telescope 18: 546549.

3. Becker G (1964) Reaktion von Insekten auf Magnetfelder, elektrische Felder und atmospherics. Zeitschtrift für angewandte Entomologie 54(14): 7588.

4. Damaschke K, Becker G (1964) Korrelation der Atmungsintensität von Termiten zu Änderungen der Impulsfolgefrequenz der atmospherics. Z Naturforsch 19(2): 157160.

5. Becker G, Gerisch W (1977) Korrelation zwischen der Fraßaktivität von Termiten und der geomagnetischen Aktivität. Zeit Für Ang Ent 84(4): 353388.

6. Nowinszky L, Puskás J (2011) The influence of solar terrestrial effects on light-trap catch of night flying insects. Biological Forum 3(1): 32-35. 


\section{Journal of Ecology and Natural Resources}

7. Nowinszky L (2003) The Handbook of Light Trapping. Savaria University Press, Szombathely, pp: 276.
8. Odor P, Iglói L (1987) An introduction to the sport's biometry (in Hungarian). ÁISH Tudományos Tanácsának Kiadása. Budapest, pp: 267. 